\title{
Synthesis, characterization and thermal behaviour on solid pyruvates of some bivalent metal ions.
}

\author{
A. B. Siqueira ${ }^{1}$, C. T. de Carvalho ${ }^{1}$, E. Y. Ionashiro ${ }^{2}$, M. Ionashiro ${ }^{1 *}$. \\ ${ }^{1}$ Instituto de Química, UNESP, CP 355, CEP 14801-970, Araraquara, SP, Brazil. \\ ${ }^{2}$ Instituto de Química, UFG, Campus II, CEP74001-979, Goiânia, GO, Brazil. \\ *Corresponding author
}

\begin{abstract}
Solid state M-L compounds, were M stands for bivalent Mn, Fe, Co, Ni, Cu, Zn and L is pyruvate, have been synthesized. Thermogravimetry and derivative thermogravimetry (TG/ DTG), differential scanning calorimetry (DSC), X-Ray powder diffractometry, infrared spectroscopy, elemental analysis, and complexometry were used to characterize and to study the thermal behaviour of these compounds. The results led to information about the composition, dehydration, ligand denticity, and thermal decomposition of the isolated compounds.
\end{abstract}

Keywords: bivalent metals, pyruvate, characterization, thermal behaviour.

\section{Introduction}

Investigations on pyruvic acid (HPy), as well as compounds derivatives of HPy, have been carried out in biological science researches. However little works on salts of pyruvic acid $\left(\mathrm{H}_{3} \mathrm{C}-\right.$ $\mathrm{CO}-\mathrm{COOH}$ ) have been described in the literature. In aqueous solutions the formation of some metal ions complexes with pyruvic acid in ratio of metal: ligand 1:1 and 1:2 have been established by the spectroscopic method [1-3]; the stability constants and thermodynamic functions of complexes formation of lanthanides with pyruvic acid: $\Delta \mathrm{G}, \Delta \mathrm{H}, \Delta \mathrm{S}$, have also been determined [4]. In the solid state, preparation of europium pyruvate [5], as well as the preparation and properties of lanthanides and yttrium pyruvates have also been described $[6,7,8]$.

The aim of this work has been to obtain bivalent metal pyruvates in solid state and to investigate by means of complexometry, elemental analysis, X-Ray powder diffractometry, infrared spectroscopy, thermogravimetry (TG) and differential scanning calorimetry (DSC).

\section{Experimental}

The sodium pyruvate with $99 \%$ purity was obtained from Sigma. Aqueous solution of sodium pyruvate $0.8 \mathrm{~mol} \mathrm{~L}^{-1}$ was made by direct weighing of the solid salt. Aqueous solutions of bivalent metal ions $0.4 \mathrm{~mol} \mathrm{~L}^{-1}$ were prepared by dissolving the corresponding chlorides.

The solid state compounds were prepared by mixing $10 \mathrm{~mL}$ solutions of the corresponding metal chlorides with $10 \mathrm{~mL}$ solution of sodium pyruvate. The resulting solutions were evaporated in a water bath until dryness. The dry compounds were washed with a mixture of water:ethanol (6:4) until chloride ions were eliminated, filtered through and dried on whatman $n^{\circ} 42$ filter paper and kept in a desiccator over anhydrous calcium chloride. For the Mn(II) and Fe(II) compounds, to avoid oxidation, all their solutions as well as the solution employed for washing their compounds were purged with nitrogen gas, even during the drying in a water bath.

In the solid state compounds, the metal ions contents were determined by complexometry with 
standard EDTA solution [9]. The metal ions contents were also estimated from their corresponding TG curves. The dehydration of the compounds was firstly pointed out by their DTG curves and subsequently confirmed by the broad endothermic peaks centered at $75-175^{\circ} \mathrm{C}$ in the respective DSC curves. The water contents were then determined from the corresponding mass losses observed in the TG curves. Next, the ligand content was also assessed from the TG curves.

$\mathrm{X}$-ray powder patterns were obtained by using a Siemens D-5000 X-Ray diffractometer with $\mathrm{CuK}_{\alpha}$ radiation $(\lambda=1,541 \AA)$ and under 40 $\mathrm{kV}$ and $20 \mathrm{~mA}$ settings. Infrared spectra for sodium pyruvate as well as for its metal-ion compounds were recorded on a Nicolet model Impact 400 FTIR Instrument in $4000-400 \mathrm{~cm}^{-1}$ range. The solid samples were pressed into $\mathrm{KBr}$ pellets.

Carbon and hydrogen were determined by microanalytical procedures with an EA 1110 CHNSO, Elemental Analyser from CE Instruments.

The TG and DTG curves were obtained using a Mettler TA 4000 thermal analysis system with an air flow of $100 \mathrm{~mL} \mathrm{~min}^{-1}$, a heating rate of $20{ }^{\circ} \mathrm{C} \mathrm{min}^{-1}$ and with sample weighing about $7 \mathrm{mg}$. An alumina crucible was used for the TG/ DTG curves.

The DSC curves were obtained with thermal analysis system model Q10 from TA Instruments. The purge gas was an air flow of $50 \mathrm{~mL}$ $\mathrm{min}^{-1}$. A heating rate of $20{ }^{\circ} \mathrm{C} \mathrm{min}^{-1}$ was adopted with samples weighing about $5 \mathrm{mg}$. Aluminium crucibles, with perforated cover, were used for recording the DSC curves.

\section{Results and Discussion}

Table 1 presents the analytical, thermoanalytical (TG) and elemental analysis (EA) data for the prepared compounds from which the general formula $\mathrm{M}(\mathrm{L})_{2} \cdot \mathrm{nH}_{2} \mathrm{O}$ can be established, where $M$ represents bivalent metals, $L$ is pyruvate and $n$ = $2(\mathrm{Cu}), 3$ (Fe, Zn), 3.5 (Mn, Co, Ni).

Table 1. Analytical and thermoanalytical (TG) data for $\mathrm{M}(\mathrm{L})_{2} \cdot \mathrm{nH}_{2} \mathrm{O}$, where $\mathrm{M}=$ bivalent metals and $\mathrm{L}=$ pyruvate.

\begin{tabular}{|c|c|c|c|c|c|c|c|c|c|c|c|c|}
\hline \multirow{2}{*}{ Compound } & \multicolumn{3}{|c|}{ Metal oxide (\%) } & \multicolumn{2}{|c|}{ L, lost (\%) } & \multicolumn{2}{|c|}{ Water (\%) } & \multicolumn{2}{|c|}{ Carbon (\%) } & \multicolumn{2}{|c|}{ Hidrogen (\%) } & \multirow{2}{*}{$\begin{array}{c}\text { Final } \\
\text { Residue }\end{array}$} \\
\hline & Calcd. & TG & EDTA & Calcd. & TG & Calcd. & TG & Calcd & E.A & Calcd & E.A & \\
\hline $\mathrm{Mn}(\mathrm{L})_{2} \cdot 3 \cdot 5 \mathrm{H}_{2} \mathrm{O}$ & 27.02 & 26.95 & 26.67 & 51.39 & 51.63 & 21.59 & 21.42 & 24.67 & 24.94 & 4.49 & 4.51 & $\mathrm{Mn}_{2} \mathrm{O}_{3}$ \\
\hline $\mathrm{Fe}(\mathrm{L})_{2} \cdot 3 \mathrm{H}_{2} \mathrm{O}$ & 27.17 & 26.87 & 27.33 & 53.80 & 54.31 & 19.03 & 18.82 & 25.37 & 25.41 & 4.27 & 4.10 & $\mathrm{Fe}_{3} \mathrm{O}_{4}$ \\
\hline $\mathrm{Co}(\mathrm{L})_{2} \cdot 3 \cdot 5 \mathrm{H}_{2} \mathrm{O}$ & 27.10 & 26.32 & 27.35 & 51.60 & 51.85 & 21.30 & 21.33 & 24.33 & 24.40 & 4.43 & 4.65 & $\mathrm{Co}_{3} \mathrm{O}_{4}$ \\
\hline $\mathrm{Ni}(\mathrm{L})_{2} \cdot 3 \cdot 5 \mathrm{H}_{2} \mathrm{O}$ & 25.25 & 25.07 & 24.90 & 53.44 & 53.68 & 21.31 & 21.25 & 24.35 & 24.03 & 4.44 & 4.30 & $\mathrm{NiO}$ \\
\hline $\mathrm{Cu}(\mathrm{L})_{2} 2 \mathrm{H}_{2} \mathrm{O}$ & 29.06 & 29.31 & 29.34 & 57.77 & 57.69 & 13.17 & 13.00 & 26.33 & 26.67 & 3.69 & 3.50 & $\mathrm{CuO}$ \\
\hline $\mathrm{Zn}(\mathrm{L})_{2} \cdot 3 \cdot 5 \mathrm{H}_{2} \mathrm{O}$ & 27.72 & 27.60 & 27.97 & 53.86 & 54.13 & 18.42 & 18.27 & 24.55 & 24.35 & 4.13 & 4.21 & $\mathrm{ZnO}$ \\
\hline
\end{tabular}

The X-ray powder diffraction patterns, Fig. 1, show that all compounds, except iron compound, have a crystalline structure. The others compounds, except for the copper compound, evidence for formation of an isomorphous series is observed. 


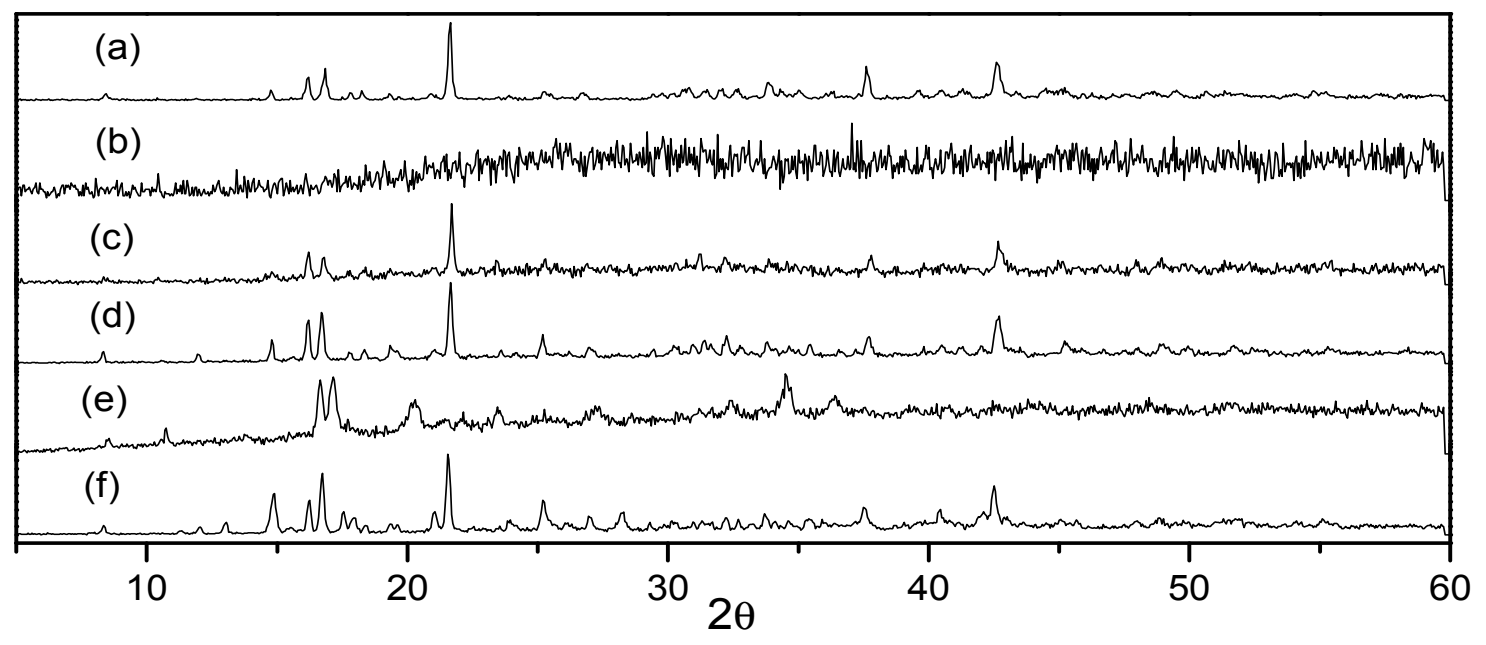

Fig. 1: X-ray powder diffraction patterns of (a) MnL2.3.5H2O; (b) FeL2.3H2O; (c) CoL3.3.5H2O; (d) NiL3.3.5H2O; (e) CuL3.2H2O; (f) ZnL3.3H2O. L= pyruvate.

The infrared spectroscopic data on sodium pyruvate and its compounds with the metal ions considered in this work are shown in Table 2. The investigation was focused mainly within $1750-1350$ $\mathrm{cm}^{-1}$ range because this region is potentially most informative in attempting to assign coordination sites. In sodium pyruvate, strong band at $1709 \mathrm{~cm}^{-1}$ is attributed to the stretching frequency of the ketonic carbonyl group and strong bands at $1654 / 1631 \mathrm{~cm}^{-1}$ and $1405 \mathrm{~cm}^{-1}$ are attributed to the anti-symmetrical and symmetrical frequencies of carboxylate group, respectively $[10,11]$. Pyruvates are also twisted in the solid state, but the dihedral angle is not larger than $25^{\circ}$, and sodium interact with both the $\alpha-C=O$ and $\mathrm{COO}^{-}$groups [12]. $\mathrm{Mn}, \mathrm{Co}, \mathrm{Ni}$ and $\mathrm{Zn}$ pyruvates are essentially identical, but Fe and Zn pyruvates show a different type of coordination, because of the increase $v_{(\mathrm{C}=\mathrm{O})}$ of these compounds. It also suggest that the interaction Fe-O and $\mathrm{Cu}-\mathrm{O}(\alpha-\mathrm{C}=\mathrm{O})$ is more weak than other compounds obtained. For the prepared compounds the infrared spectra show a broad band in the range of $3000-3500 \mathrm{~cm}^{-1}$ is attributed to hydration water.

Table 2. Spectroscopic data for sodium pyruvate and compounds with bivalent metal ions

\begin{tabular}{lcccc}
\hline \multicolumn{1}{c}{ Compound } & $\mathrm{N}_{(\mathrm{O}-\mathrm{H})} \mathrm{H}_{2} \mathrm{O}^{\mathrm{b}}$ & $\mathrm{N}_{(\mathrm{C}=\mathrm{O})}^{\mathrm{c}}$ & $\mathrm{N}_{\text {asym (COO })}{ }^{-\mathrm{d}}$ & vsym (COO-)d \\
\hline $\mathrm{Na}(\mathrm{Py})$ & - & $1709 \mathrm{~s}$ & $1654,1631 \mathrm{~s}$ & $1405 \mathrm{~s}$ \\
$\mathrm{Mn}(\mathrm{Py})_{3} \cdot 3 \cdot 5 \mathrm{H}_{2} \mathrm{O}$ & $3151_{\mathrm{br}}$ & $1704 \mathrm{~s}$ & $1674,1605 \mathrm{~s}$ & $1373 \mathrm{~s}$ \\
$\mathrm{Fe}(\mathrm{Py})_{3} \cdot 3 \mathrm{H}_{2} \mathrm{O}$ & $3376_{\mathrm{br}}$ & $1734 \mathrm{~m}$ & $1635,1624 \mathrm{~s}$ & $1383 \mathrm{~s}$ \\
$\mathrm{Co}(\mathrm{Py}) 3.3 .5 \mathrm{H} 2 \mathrm{O}$ & $3244_{\mathrm{br}}$ & $1705 \mathrm{~s}$ & $1678,1605 \mathrm{~s}$ & $1396 \mathrm{~s}$ \\
$\mathrm{Ni}(\mathrm{Py}) 3.3 .5 \mathrm{H} 2 \mathrm{O}$ & $3320_{\mathrm{br}}$ & $1703 \mathrm{~s}$ & $1678,1602 \mathrm{~s}$ & $1398 \mathrm{~s}$ \\
$\mathrm{Cu}(\mathrm{Py})_{3} \cdot 2 \mathrm{H}_{2} \mathrm{O}$ & $3408_{\mathrm{br}}$ & $1729 \mathrm{~s}$ & $1654 \mathrm{br}$ & $1398 \mathrm{~s}$ \\
$\mathrm{Zn}(\mathrm{Py})_{3} \cdot 3 \mathrm{H}_{2} \mathrm{O}$ & $3110^{\mathrm{br}}$ & $1712 \mathrm{~s}$ & $1676 \mathrm{br}$ & $1394 \mathrm{~s}$ \\
\hline
\end{tabular}

s: strong, m: medium,

br - broad; $\mathrm{N}_{\text {asym (COO ) }}^{-}$and $\mathrm{N}_{\text {sym (COO ) }}^{-}$: symmetrical and anti-symmetrical vibrations of the COO- group, respectively

$\mathrm{N}_{\text {asym (COO) }}^{-} \mathrm{N}_{\text {asym (COO) NaL - }} \mathrm{N}_{\text {asym (COO ) metal complex) }}$

$\mathrm{N}_{(\mathrm{C}=0)}$; : ketonic carbonyl stretching frequency.

$\mathrm{N}_{(\mathrm{O}-\mathrm{H})}$ : hydroxyl group stretching frequency; 
The TG and DTG curves of the compounds are shown in Fig. 2. These curves show mass losses in three consecutive and/or overlapping steps and without evidence concerning the formation of stable anhydrous compounds. As previously stressed, the temperatures corresponding to the mass losses due to dehydration were depicted from the DTG curves.
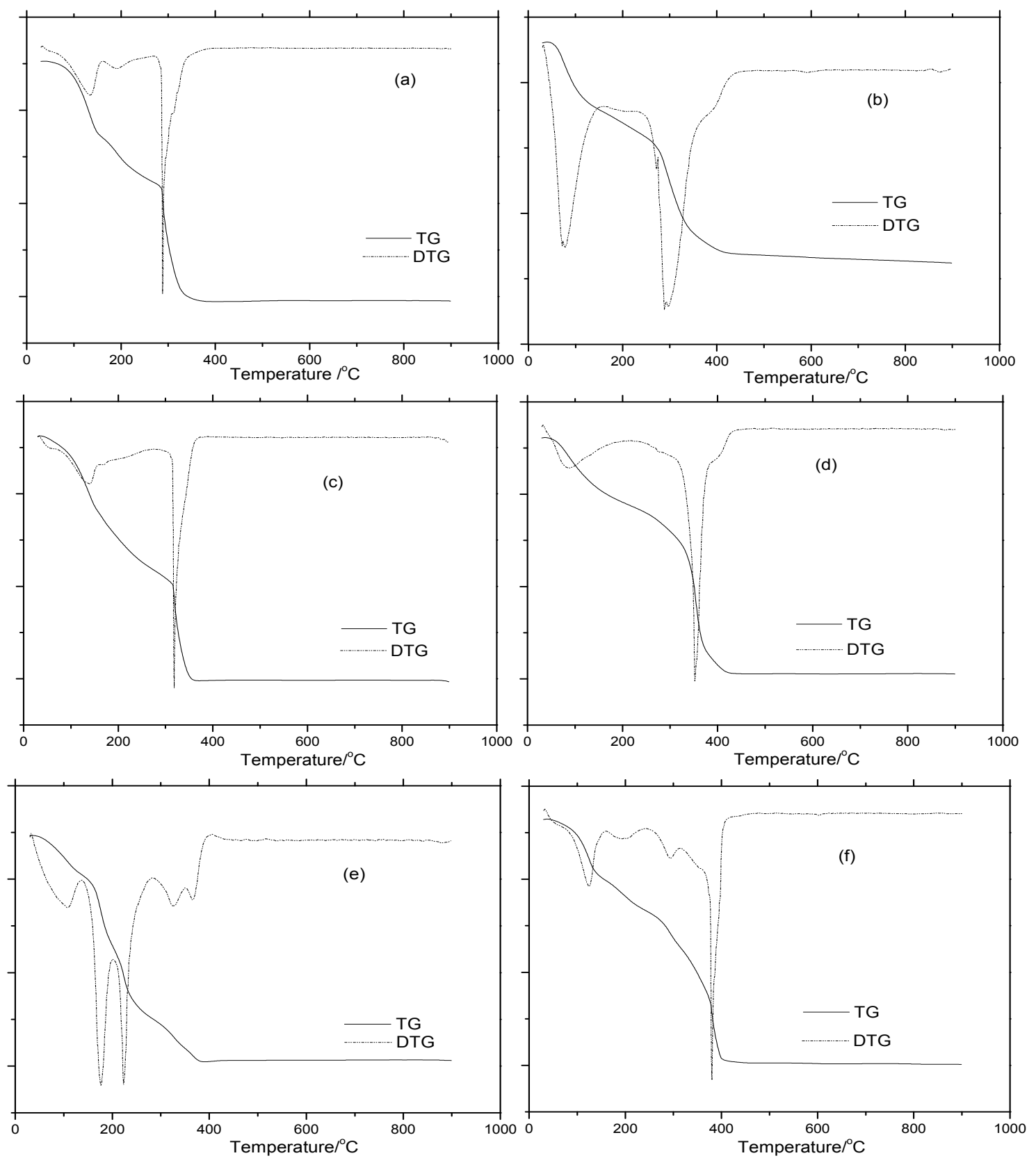

Fig. 2: The TG/DTG curves of (a) $\mathrm{MnL}_{2} \cdot 3.5 \mathrm{H}_{2} \mathrm{O}$ (m=7.053 mg); (b) $\mathrm{FeL}_{2} \cdot 3 \mathrm{H}_{2} \mathrm{O}$ (4.600 mg); (c) $\mathrm{CoL}_{3} \cdot 3 \cdot 5 \mathrm{H}_{2} \mathrm{O}$ (7.254 mg); (d) $\mathrm{NiL}_{3} \cdot 3.5 \mathrm{H}_{2} \mathrm{O}$ (7.295 mg); (e) $\mathrm{CuL}_{3} \cdot 2 \mathrm{H}_{2} \mathrm{O}$ (6.933 mg); (f) $\mathrm{ZnL}_{3} \cdot 3 \mathrm{H}_{2} \mathrm{O}$ (7.289 mg). L= pyruvate. 
For all compounds, the first mass loss up to $140{ }^{\circ} \mathrm{C}(\mathrm{Fe}, \mathrm{Cu})$ and $150{ }^{\circ} \mathrm{C}(\mathrm{Mn}, \mathrm{Co}, \mathrm{Ni}, \mathrm{Zn})$ is attributed to dehydration, which occurs in a single step.

Immediately after the dehydration the thermal decomposition of these compounds occurs in two (Co, Ni, Cu, Zn) and three (Mn, Fe) steps, with mass losses in each step characteristic of each compound.

For the manganese compound, Fig. 2(a), the first mass loss observed between 50 and $150{ }^{\circ} \mathrm{C}$ is due to dehydration, with loss of $3.5 \mathrm{H}_{2} \mathrm{O}$ (calcd. $=21.59 \%$; $\mathrm{TG}=21.42 \%$ ). The thermal decomposition of the anhydrous compound occurs in two steps, between $150-290{ }^{\circ} \mathrm{C}$ and $290-390{ }^{\circ} \mathrm{C}$, with losses of 16.87 and $34.76 \%$, respectively. The total mass loss up to $390{ }^{\circ} \mathrm{C}$ is in agreement with the formation of $\mathrm{Mn}_{2} \mathrm{O}_{3}$ (Calcd $=72.98 \%$; $\mathrm{TG}=$ $73.05 \%)$. The mass loss observed between 920$980{ }^{\circ} \mathrm{C}$, is assigned to the reduction of $\mathrm{Mn}_{2} \mathrm{O}_{3}$ to $\mathrm{Mn}_{3} \mathrm{O}_{4}(\mathrm{Calcd}=0.91 \%$; $\mathrm{TG}=0.90 \%)$ and confirmed by X-ray powder diffractometry, and in agreement with the thermal decomposition of manganese 4-methylbenzylidenepyruvate [13].

Literature reports on the thermal stability and reduction temperature of $\mathrm{Mn}_{2} \mathrm{O}_{3}$ are in disagreement among themselves [14-16] and with the data obtained in this work. This behaviour concerning manganese oxides has already been pointed out [14]; it is reported that the properties significantly depend on the preparation conditions, structural properties of the oxides and upon operational parameters during the reduction step [14].

For the iron compound, Fig. 2(b), the first mass loss between $50-140{ }^{\circ} \mathrm{C}$ is due to dehydration with loss of $3 \mathrm{H}_{2} \mathrm{O}$ (Calcd $=19.03 \%$, TG $=$ $18.82 \%)$. After the dehydration the thermal decomposition occurs in three steps, being the first two between $140-270{ }^{\circ} \mathrm{C}$ and $270-425^{\circ} \mathrm{C}$ fast processes, followed by a slow process for the third step $\left(425-900{ }^{\circ} \mathrm{C}\right)$ with losses of $13.38,37.78$ and $3.15 \%$ respectively. The total mass loss up to 900 ${ }^{\circ} \mathrm{C}$ is in agreement with the formation of $\mathrm{Fe}_{3} \mathrm{O}_{4}$ (Calcd. $=72.83 \%$, TG $=73.13 \%$ ).

The formation of $\mathrm{Fe}_{3} \mathrm{O}_{4}$ was also confirmed by the black colour and magnetic property of the residue and by $\mathrm{X}$-ray diffractometry.

For the cobalt compound, Fig. 2(c) the first mass loss between $40-150{ }^{\circ} \mathrm{C}$ is due to dehydra- tion with loss of $3.5 \mathrm{H}_{2} \mathrm{O}$ (calcd. $=21.30 \%$, TG $=21.33 \%$ ). The thermal decomposition of the anhydrous compound occurs in two steps, between $150-320{ }^{\circ} \mathrm{C}$ and $320-370{ }^{\circ} \mathrm{C}$, with losses of 23.33 and $28.52 \%$, respectively. The total mass loss up to $370{ }^{\circ} \mathrm{C}$ is in agreement with the formation of $\mathrm{Co}_{3} \mathrm{O}_{4}$ (Calcd. $=72.90 \%$, $\mathrm{TG}=73.18 \%$ ). The mass loss observed between 900 and $930{ }^{\circ} \mathrm{C}$, is ascribed to the reduction of $\mathrm{Co}_{3} \mathrm{O}_{4}$ to $\mathrm{CoO}$ (Calcd. $=1.81 \%$; $\mathrm{TG}=1.74 \%)$ in agreement with the literature $[17$, $18]$.

For the nickel compound, Fig. 2(d) the first mass loss between $50-150{ }^{\circ} \mathrm{C}$ is due to dehydration with loss of $3.5 \mathrm{H}_{2} \mathrm{O}$ (Cald. $=21.31 \%$, TG $=21.33 \%)$. The thermal decomposition of the anhydrous compound occurs in two steps, between $150-300{ }^{\circ} \mathrm{C}$ and $300-440{ }^{\circ} \mathrm{C}$ with losses of 11.78 and $41.90 \%$, respectively. The total mass loss up to $440{ }^{\circ} \mathrm{C}$ is in agreement with the formation of $\mathrm{NiO}(\mathrm{Calcd}=74.75 \%, \mathrm{TG}=74.93 \%)$ and confirmed by X-ray diffractometry.

For copper compound, Fig. 2(e) the first mass loss between 40 and $140{ }^{\circ} \mathrm{C}$ is due to dehydration with loss of $2 \mathrm{H}_{2} \mathrm{O}$ (Calcd. $=13.17 \%$, $\mathrm{TG}=13.00 \%$ ). After the dehydration although the DTG curve to show mass loss in four overlapping steps, the TG curve suggests two steps between $140-245{ }^{\circ} \mathrm{C}$ and $245-400{ }^{\circ} \mathrm{C}$ with losses of 38.69 and $19.70 \%$, respectively and formation of a mixture of $\mathrm{Cu}(\mathrm{I})$ and $\mathrm{Cu}$ (II) oxides. The mass gain between $400-430{ }^{\circ} \mathrm{C}$ is attributed to the oxidation of $\mathrm{Cu}(\mathrm{I})$ to $\mathrm{Cu}(\mathrm{II})$. The total mass loss up to $430{ }^{\circ} \mathrm{C}$ is in agreement with the formation of $\mathrm{CuO}$ (Calc. $=70.94 \%, \mathrm{TG}=70.69 \%)$ and confirmed by $\mathrm{X}$-ray diffractometry.

For the zinc compound, Fig. 2(f) the first mass loss between 50 and $150{ }^{\circ} \mathrm{C}$ is due to dehydration with loss of $3 \mathrm{H}_{2} \mathrm{O}$ (Calcd. $=18.42 \%$, $\mathrm{TG}=18.27 \%)$. The thermal decomposition of the anhydrous compound occurs in two steps between $150-275{ }^{\circ} \mathrm{C}$ and $275-450{ }^{\circ} \mathrm{C}$ with losses of 12.89 and $41.24 \%$, respectively. The total mass loss up to $450{ }^{\circ} \mathrm{C}$ is in agreement with the formation of $\mathrm{ZnO}(\mathrm{Calcd} .=72.28 \%, \mathrm{TG}=72.40 \%)$ and confirmed by X-ray diffractometry. 
The DSC curves of the compounds are shown in Fig. 3. These curves show endothermic and exothermic peaks that all accord with the mass losses observed in the TG curves. The broad endothermic peak at $162{ }^{\circ} \mathrm{C}(\mathrm{Mn}), 129{ }^{\circ} \mathrm{C}(\mathrm{Fe}), 170{ }^{\circ} \mathrm{C}(\mathrm{Co}), 180{ }^{\circ} \mathrm{C}(\mathrm{Ni}), 134{ }^{\circ} \mathrm{C}(\mathrm{Cu})$ and $161{ }^{\circ} \mathrm{C}(\mathrm{Zn})$ is attributed to the dehydration. The dehydration enthalpies found for these compounds were: 130.3, 80.7, 133.6, 135.1, 63.2 and $108.6 \mathrm{~kJ} \mathrm{~mol}^{-1}$, respectively.

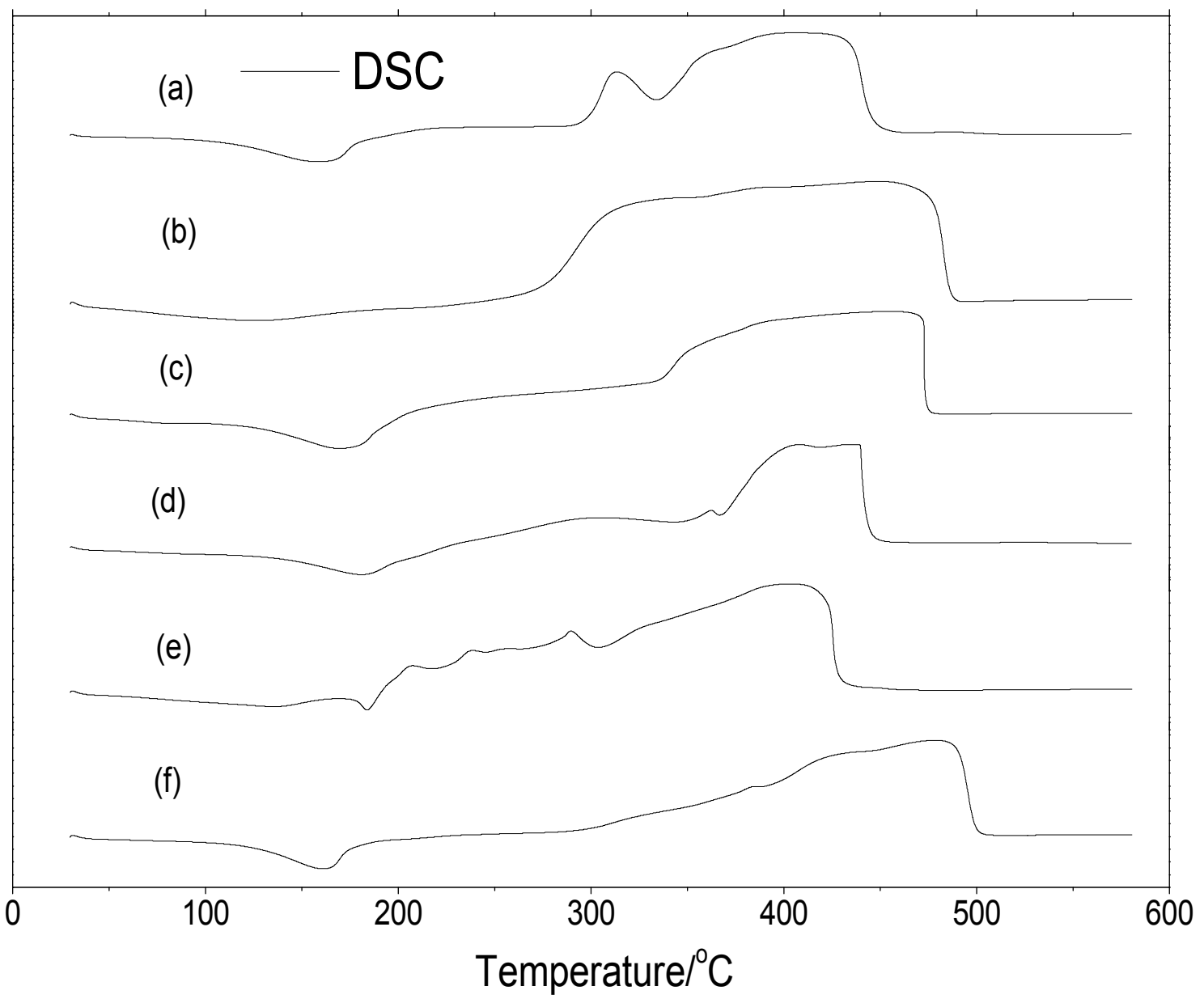

Fig. 3: The DSC curves of of (a) $\mathrm{MnL}_{2} \cdot 3.5 \mathrm{H}_{2} \mathrm{O}$ (m=5.060 mg); (b) $\mathrm{FeL}_{2} \cdot 3 \mathrm{H}_{2} \mathrm{O}\left(5.030 \mathrm{mg}\right.$ ); (c) $\mathrm{CoL}_{3} \cdot 3.5 \mathrm{H}_{2} \mathrm{O}$ (5.026 $\mathrm{mg}$ ); (d) $\mathrm{NiL}_{3} .3 .5 \mathrm{H}_{2} \mathrm{O}$ (5.033 mg); (e) $\mathrm{CuL}_{3} .2 \mathrm{H}_{2} \mathrm{O}$ (5.012 mg); (f) $\mathrm{ZnL}_{3} \cdot 3 \mathrm{H}_{2} \mathrm{O}$ (4.992 mg). L= pyruvate

The endothermic peak at $184{ }^{\circ} \mathrm{C}$ that precede the exothermic events, observed only for copper compound, is attributed to the initial thermal decomposition. The exotherms observed for all the compounds with evidence of several overlapping events between $280-530{ }^{\circ} \mathrm{C}(\mathrm{Mn}), 225-500$ ${ }^{\circ} \mathrm{C}(\mathrm{Fe}), 210-480{ }^{\circ} \mathrm{C}(\mathrm{Co}), 210-460{ }^{\circ} \mathrm{C}$ (Ni), 190$470{ }^{\circ} \mathrm{C}(\mathrm{Cu})$ and $280-515^{\circ} \mathrm{C}(\mathrm{Zn})$, are attributed to the thermal decomposition of the anhydrous compounds, where the oxidation of the organic matter takes place in overlapping steps. 


\section{Conclusions}

From TG curves, elemental analysis and complexometria results a general formula could be established for these compounds in the solid state.

The X-ray powder patterns of the synthesized compounds have a crystalline structure, except the iron compound.

The infrared spectroscopic data suggest that the pyruvate acts as a tridentate ligand towards the metal ions considered in this work.

The TG/DTG and DSC curves, provided information about the thermal stability and thermal decomposition of these compounds.

\section{Acknowledgements}

The authors thank FAPESP (Procs. 90/29324 and 2005/00926-4), CNPQ and CAPES Foundations (Brazil) for financial support.

Síntese, caracterização e comportamento térmico dos piruvatos de alguns metais bivalentes no estado sólido.

Received August 132009

Accepted November 042009

Resumo: Compostos M-L foram sintetizados no estado sólido, onde M representa os íons bivalentes Mn, Fe, Co, Ni, Cu e Zn e L é o ânion piruvato. Esses compostos foram caracterizados e estudados utilizando-se as técnicas: termogravimetria e termogravimetria derivada (TG/DTG), calorimetria exploratória diferencial (DSC), difratometria de raios X pelo método do pó, espectroscopia de absorção na região do infravermelho, análise elementar e complexometria. Os resultados forneceram informações com respeito à composição, desidratação, sítio de coordenação e decomposição térmica dos compostos isolados.

Palavras chave: metais bivalentes, piruvato, caracterização e comportamento térmico.

\section{References}

[1] S. Ramamothy, A. Raghavan, V.R. Vijayaraghavan, M. Schutappa, J. Inorg. Chem., 31(1969) 1851.

[2] J. J. Kim, T.E Cummings, J. A. Cok, Anal. Letters, 5 (1972) 703.

[3] V. Veervalur. Raaghavan, D. L. Leussing, J.Indian Chem. Soc., 54(1977) 68.

[4] K.N. Mc. Coy, J. Am. Chem. Soc., 61(1939) 2455.

[5] G. B. Choppin, R. Cannon, Inorg. Chem., 19 (1980) 1889.

[6] W.Brzyska, W. Ożga, Polish J. Chem., 58 (1984) 385.

[7] W.Brzyska, W. Ożga, Polish J. Chem., 59 (1985) 233.

[8] A. B. Siqueira, C. T. de Carvalho, E. C. Rodrigues, E. Y. Ionashiro, G Bannach, M. Ionashiro, Ecl. Quim., 32(4) (2007) 49.

[9] C. N. de Oliveira, M. Ionashiro, C. A. F. Graner, Ecl. Quim., 10 (1985)7.

[10] K. Duczmal, M. Dorowska, E. D. Raczyńska, Vib. Spectrosc. 37 (2005) 77.

[11] H. Hanai, A. Kuwac, Y. Sugawa, K-K. Kunimoto, S. Maeda, J. Molec. Struct., 837 (2007) 101.

[12] S. S. Tavale, L. M. Pant, A. B. Biswas, Acta Cryst., 14 (1961) 1281.
[13] I. A. Petroni, F. L. Fertonani, C. B. Melios, M. Ionashiro, Thermochim. Acta, 400 (2003) 187.

[14] C. Gonzales, J. I. Gutierrez, J. R. Gonzales-Velasco, A. Cid, A. Arranz, J. F. Arranz, J. Therm. Anal. 47 (1996) 93.

[15] D. Czakis-Sulikowska, J. Katuzna, J. Therm. Anal. Cal. 58 (1999) 51.

[16] L. Biernacki, S. Pokrzywnicki, J. Therm. Anal. Cal. 55 (1999) 227.

[17] G. A. El-Shobaki, A. S. Ahmad, A. N. Al-Naomi, H. G. El-Shobaky, J. Therm. Anal. 46 (1996) 1801.

[18] Z. P. Xu, H. C. Zeng, J. Mater. Chem., 8 (1998) 2499. 